Raven-Big River, 5; Nipawin, 9; Rose Valley, 2; Somme, 3; Torch River, 3. (Swan River, 2); (Wallwort, 1).

Black-capped Chickadee-Big River, 41; Bladworth, 1; Broadview, 5; Brora, 6; Dilke, 2; Grenfell, 5; McLean, 6; Naicam, 6; Nipawin, 8; Pathlow, 2; Rose Valley, 40; Round Lake, 4; Saltcoats, 2; Saskatoon, 4; Sheho, 5; Somme, 8; Spirit Lake, 6; Swan River, 4; Tisdale, 18; Wallwort, 5; Yorkton, 63. (Skull Creek, $5)$; (Torch River, 5.)

Hudsonian Chickadee-Somme, 20; Swan River, 4; Torch River, 2. (Yorkton, 1).

White-breasted Nuthatch-Big River, 4; Somme, 4.

Brown Creeper-(Somme, 2).

Golden-crowned Kinglet-Somme, 1.

Amer. Robin-Yorkton, 1. (Skull Creek, 1).

Bohemian Waxwing-Broadview, 10; Nipawin, 807; Round Lake, 6; Saltcoats, 40; Saskatoon, 31; Tisdale, 80; Yorkton, 29. (McLean, 5); (Naicam, 3); (Sheho, 2); (Skull Creek, 450); (Spirit Lake, 25); (Swan River, 17); (Torch River, 20).

Northern Shrike-Nipawin, 1. (Bladworth, 1); (Pathlow, 1); (Torch River, 1).

European Starling-Nipawin, 3; Swan River, 22. (Dilke, 1).

English Sparnow-Bladworth, 25; Bredenbury, 6; Broadview, 24; Brora, 50; Dilke, 20; Grenfell, 138; Hawarden, 200; Naicam, 11; Nipawin, 1500; Pathlow, 50; Regina, 20; Rose Valley, 50; Round Lake, 3; Saltcoats, 9; Saskatoon, 875; Somme 1; Spirit Lake, 50; Swan River, many; Tisdale, many; Yorkton, 1030. (McLean, 26); (Skull Creek, 68); (Torch River, 25).

Western Meadowlark-(Dilke, 1).

Red-winged Blackbird-(Skull Creek, 1).

Brewer's Blackbird-Yorkton, 1.
Evening Grosbeak-Nipawin, 56; Sheho, 12; Spirit Lake, 18; Swan River, 5. (Naicam, 5); (Somme, 6); (Tisdale, 6); (Torch River, 12).

Pine Grosbeak - Bredenbury, 2; Broadview, 3; Grenfell, 25; Naicam, 9; Nipawin, 38; Rose Valley, 20; Round Lake, 9; Saskatoon, 4; Sheho, 16; Spirit Lake, 1; Swan River, 4; Tisdale, 4; Wallwort, 5; Yorkton, 15. (Big River, 5); (Skull Creek, 4); (Somme, 101); (Torch River, 1).

Hoary Redpoll-Nipawin, 50; Swan River, 15. (Somme, 10); (Torch River, 5).

Common Redpoll - Broadview, 2; Brora, 10; Dilke, 25; Grenfell, 446; Naicam, 3; Nipawin, 3651; Round Lake, 40; Rose Valley, 50; Saskatoon, 405; Sheho, 6; Spirit Lake, 30; Swan River, 92; Torch River, 25; Wallwort, 7; Yorkton, 96. (Big River, 42); (Bladworth, 17); (Pathlow, 35); (Somme, 12); (Skull Creek, 21).

Vesper Sparrow-Saltcoats, 1.

Slate-colored Junco-Saskatoon, 4; Yorkton, 1.

Tree Sparrow-(Skull Creek, 18).

Snow Bunting-Bladworth, 29; Dilke, 150; Hawarden, 4; Naicam, 35; Nipawin, 11,567; Pathlow, 60; Regina, 8; Rose Valley, flocks; Saltcoats, 14; Saskatoon, 250; Sheho, 100; Torch River, 400; Yorkton, 520. (Big River, 150); (Broadview, 25); (Grenfell, flock); (Skull Creek, 700 ); (Somme, 300); (Spirit Lake, 18); (Swan River, 36).

\section{ANIMAL TRAVELLERS}

Over the silent snowfields, Empty of life and heat, See how the tracks go winding, Tracks of the swift small feet! Here in the silent snowfields, When there is no man near, Many a furry rabbit, Many a gentle deer Come on their own strange errands, Vanish swift as they came, Leaving for human travellers This signature of their name.

Mary Garland Coleman. Regina, Sask. 